\title{
Characterization of a molybdenum-reducing Bacillus sp. strain khayat with the ability to grow on SDS and diesel
}

\begin{abstract}
Molybdenum and heavy metals are toxicants that are needed to be removed from the environment as they are non-biodegradable and pose a serious threat to the ecology. A previously isolated keratin-degrading Bacillus sp. strain khayat was shown to be able to reduce molybdenum (sodium molybdate) to molybdenum blue (Mo-blue). Reduction occurred optimally at the pHs of between 5.8 and 6.8 and temperatures of between 25 and 34 ${ }^{\circ} \mathrm{C}$. Glucose was the best electron donor for supporting molybdate reduction followed by sucrose, fructose, glycogen, lactose, meso-inositol and glycerol in descending order. Other requirements include a phosphate concentration between 5.0 and $7.5 \mathrm{mM}$ and a molybdate concentration of between 10 and $20 \mathrm{mM}$. The absorption spectrum of the Mo-blue produced was similar to previous Mo-reducing bacterium, and closely resembles a reduced phosphomolybdate. Molybdenum reduction was inhibited by $\mathrm{Hg}$ (ii), $\mathrm{Ag}$ (i), $\mathrm{Cu}$ (ii), As (v) and $\mathrm{Pb}$ (ii) at 84.7, 78.9, 53.5, 36.8 and $27.7 \%$, respectively. Analysis using phylogenetic analysis resulted in a tentative identification of the bacterium as Bacillus sp. strain khayat. The bacterium was unable utilize any of the xenobiotics as sources of electron donor for reduction but the bacterium was able to grow on diesel and SDS. The ability of this bacterium to detoxify several toxicants makes this bacterium an important tool for bioremediation of multiple toxicants.
\end{abstract}

Keyword: Molybdenum-reducing bacteria; Molybdate; Bacillus sp 